\title{
APSA Announces 2018 Small Research Grant Recipients
}

\begin{abstract}
A
PSA is delighted to announce 19 Small Research Grant recipients in 2018 , selected from over 50 applications through a competitive peer review process. In total, APSA distributed $\$ 40,000$ in small research grant awards ranging from $\$ 1,500-\$ 2,500$ each. The APSA Small Research Grant Program provides funding for research conducted by political scientists not employed at PhD-granting departments, or who are in non-tenure track or contingent positions ineligible for departmental funding. The program supports research across all fields of political science. Prior grant recipients have utilized funding to develop working papers and conference presentations, leading to published journal articles, books, and book chapters. Past grants have also benefited students serving as research assistants or coauthors. Several recipients have been able to use the APSA grant as seed money to gain additional funding. Congratulations to the following awardees:
\end{abstract}

- "Mapping the Refugee Net: Border Crossing and Technology in the Mediterranean" by Malasree Neepa Acharya, University of Delaware

- "Socio-Political Identity Transformations: The Rohingya Refugee Crisis in South and Southeast Asia" by Srobana Bhattacharya, Georgia Southern University

- "Model Cooperator and Cheap Talkers: Explaining State Cooperation with the International Criminal Court" by Franziska Boehme, Gettysburg College

- "Gaps in Political Knowledge by Race and Ethnicity" by Tabitha Bonilla, Northwestern University

- "On the Origins and Evolution of Colonial Property Rights, India 1757-190o" by Abhishek Chatterjee, University of Montana

- "Claiming Belonging: Muslim American Advocacy in an Era of Islamophobia" by Emely Cury Tohma, Northeastern University

- "Losing Power: African Americans and Racial Polarization in Tennessee Politics, 2000-2012" by Sekou Franklin, Middle Tennessee State University

- "Global Business Districts: Socio-spatial Order in the Postcolonial City" by Kevin Funk, Spring Hill College

- "Bringing Lobbyists Back In: The Leadership Conference on Civil Rights and the Postwar Development of Civil Rights Policy" by Shamira Gelbman, Wabash College
- "Japan between War and Peace" by Noriyuki Katagiri, Saint Louis University

- "Understanding the Credibility of Threats in International Security: An Experimental Analysis" by Danielle Lupton, Colgate University

- "Disability-Inclusive Communities of Care: Geel and L'Arche"by Lorraine McCrary, Wabash College

- “Women's Participation in an Urban Revolution: Gender and the Revolution of Dignity in Ukraine" by Olena Nikolayenko, Fordham University

- "Israel's Securitization Dilemma: The Battle for Legitimacy of the Jewish State" by Ronnie Olesker, St. Lawrence University

- "EU Regional Representation and City Innovation in Portugal" by David Rossbach, Chatham University

- "Quotidian Democracy: The Local Roots of Accountability in Rural India" by Marck Schneider, Pitzer College

- "Mississippi University for Women v. Hogan and the Development of Sex Discrimination Law" by Donna Schuele, California State University-Los Angeles

- "Social Policy and Governance in Asia: The Role of 'Sandwich Coalitions' in State-Building" by Arun Swamy, University of Guam

- "Roles and Goals: Stereotypes of Legislative and Executive Office and the Women in Them" by Jennie SweetCushman, Chatham University 